\title{
Eradication of Helicobacter pylori in patients with duodenal ulcer lowers basal and peak acid outputs to gastrin releasing peptide and pentagastrin
}

\author{
A W Harris, P A Gummett, J J Misiewicz, J H Baron
}

\begin{abstract}
Background-Patients with duodenal ulcer (DU) have high basal (BAO) and peak (PAO) acid outputs. The effect of Helicobacter pylori eradication on these variables is unclear.

Aim-To discover if gastric acid hypersecretion in patients with $D U$ is caused by H pylori.

Patients and methods-BAO, gastrin releasing peptide (GRP), and pentagastrin stimulated PAO in $10 \mathrm{H}$ pylori negative controls, and in $10 \mathrm{H}$ pylori positive patients with DU was measured before and six months after $H$ pylori eradication. $H$ pylori status was determined by histology, culture, and by the ${ }^{13} \mathrm{C}$-urea breath test. After collecting a 30 minute basal aspirate, GRP $40 \mathrm{pmol} / \mathrm{kg} / \mathrm{h}$ was infused for 45 minutes, and after a 30 minute washout, pentagastrin $6 \mu \mathrm{g} / \mathrm{kg}$ was injected intramuscularly.

Results-Basal and stimulated acid output $\left(\right.$ PAO $_{\mathrm{GRP}}$ and PAO $_{\mathrm{Pg}}$ ) were significantly higher in $H$ pylori positive DU than in $H$ pylori negative controls. Six months after $H$ pylori eradication, basal and stimulated acid outputs were all significantly lower than before $H$ pylori eradication.

Conclusions-This study has shown that BAO, PAO ${ }_{G R P}$, and PAO Pg $_{\mathrm{Pr}}$ are higher in $H$ pylori positive $D U$ than in $H$ pylori negative controls. All decreased significantly six months after $H$ pylori eradication, to fall within the range of controls. These results are compatible with a hypothesis that acid hypersecretion in duodenal ulcer disease is caused by $H$ pylori infection.
\end{abstract}

(Gut 1996; 38: 663-667)

Keywords: Helicobacter pylori, gastric acid output, gastric releasing peptide.

Accepted for publication 9 November 1995
Helicobacter pylori is found in more than $95 \%$ of patients with duodenal ulcer (DU) and its eradication decreases recurrence of DU from $80 \%$ to less than $2 \%$ in 12 months. ${ }^{1}$ Both $H$ pylori and acid hypersecretion have a role in the pathogenesis of DU, but it is not clear whether gastric acid hypersecretion in DU is caused by this infection.

Patients with DU have about double normal basal (BAO) and stimulated peak acid outputs (PAO), ${ }^{2}$ but the effect of $H$ pylori eradication on these variables is unclear. Two groups of investigators have reported a significant fall in BAO.$^{34}$ A $66 \%$ decrease in gastrin releasing peptide (GRP) stimulated PAO (PAO GRP ), in patients with DU one month after $H$ pylori eradication was also recorded. ${ }^{4}$ However, other studies have not shown significant changes in BAO or pentagastrin stimulated PAO $\left(\mathrm{PAO}_{\mathrm{Pg}}\right)$ in patients with DU studied up to one year after $H$ pylori eradication (Table I). ${ }^{35-7} \mathrm{We}$ have therefore measured $\mathrm{BAO}$, $\mathrm{PAO}_{\mathrm{GRP}}$, and $\mathrm{PAO}_{\mathrm{Pg}}$ in $H$ pylori negative controls and $H$ pylori positive patients with $\mathrm{DU}$ before and six months after $H$ pylori eradication.

\section{Subjects and methods}

We studied $H$ pylori negative healthy volunteers without dyspepsia and with a normal endoscopy, and $10 \mathrm{H}$ pylori positive patients with symptomatic and endoscopically diagnosed DU. Eight of 10 patients with DU were restudied six months after $H$ pylori eradication with omeprazole $20 \mathrm{mg}$ twice daily and amoxycillin $1 \mathrm{~g}$ twice daily, given for two weeks (Table II). None of the subjects had taken antisecretory medication within seven days of the studies and the patients with DU had not taken non-steroidal anti-inflammatory drugs (NSAIDs). The proportions of cigarette smokers in the two groups were similar.

Determination of $\mathrm{H}$ pylori status $H$ pylori status was determined by histology (antral, body, and duodenal bulb biopsy specimens routinely processed and stained

TABLE II Details of subjects studied

\begin{tabular}{llll}
\hline Group & Controls & $D U$ & DU follow up \\
\hline Endoscopy & Normal & DU & Normal \\
H pylori status & Negative & Positive & Negative \\
Patients (n) & 10 & 10 & 8 \\
Men & 4 & 7 & 6 \\
Age mean (range ) (y) & $33(24-40)$ & $37(22-58)$ & $39(24-58)$ \\
Current smokers & 2 & 3 & 3 \\
\hline
\end{tabular}

TABLE I Acid secretion $(\mathrm{mmol} / \mathrm{h})$ before and after $\mathrm{H}$ pylori eradication

\begin{tabular}{|c|c|c|c|c|c|c|c|c|}
\hline \multirow[b]{2}{*}{ Reference } & \multirow[b]{2}{*}{ Number } & \multicolumn{3}{|c|}{ H pylori positive $D U$} & \multicolumn{3}{|c|}{ After $\mathrm{H}$ pylori eradication } & \multirow{2}{*}{$\begin{array}{l}\text { Follow } \\
\text { up } \\
\text { (months) }\end{array}$} \\
\hline & & $B A O$ & $P A O_{\mathrm{GRP}}$ & $P A O_{\mathrm{Pg}}$ & $B A O$ & $P A O_{\mathrm{GRP}}$ & $P A O_{\mathrm{Pg}}$ & \\
\hline Present study & 10 & 9 & 31 & 43 & $3^{\star}$ & $11^{\star}$ & $29^{\star}$ & 6 \\
\hline El-Omar et al 4 & 11 & $6 \cdot 6$ & 37 & & $3 \cdot 6^{\star}$ & $13 \cdot 7^{\star}$ & & 1 \\
\hline El-Omar et al ${ }^{4}$ & 8 & & 38 & & & $7 \cdot 5^{\star}$ & & 12 \\
\hline Fullarton $e t a l^{5}$ & $\begin{array}{l}8 \\
(6)\end{array}$ & $10 \cdot 7$ & & $34 \cdot 7$ & $\begin{array}{l}6 \cdot 7 \\
(10)\end{array}$ & & $\begin{array}{l}30 \\
(31)\end{array}$ & $\begin{array}{c}1 \\
(12)\end{array}$ \\
\hline Levi et al ${ }^{13}$ & 10 & $4 \cdot 1$ & & $46 \cdot 4$ & $4 \cdot 5$ & & 46 & $<1$ \\
\hline Moss et $\mathrm{al}^{6}$ & 6 & $6 \cdot 3$ & & 46 & 3.8 & & 48 & 12 \\
\hline Moss $\mathrm{et} \mathrm{al}^{3}$ & 9 & $8 \cdot 3$ & & 37 & $2 \cdot 6^{\star}$ & & 37 & 1 \\
\hline Chiba et al ${ }^{7}$ & 12 & 7.9 & & $45 \cdot 5$ & $6 \cdot 1$ & & $34 \cdot 5$ & 1 \\
\hline Graham $^{29}$ & 1 & $7 \cdot 8$ & & 52 & $3 \cdot 8$ & & $34 \cdot 5$ & 12 \\
\hline
\end{tabular}

$\star$ Denotes significant decrease $(\mathrm{p}<0.05)$ after $H$ pylori eradication. Acid outputs are expressed as means or medians depending on the original data. Figures in parentheses refer to a 12 month follow up study on six of eight patients studied at one month. 


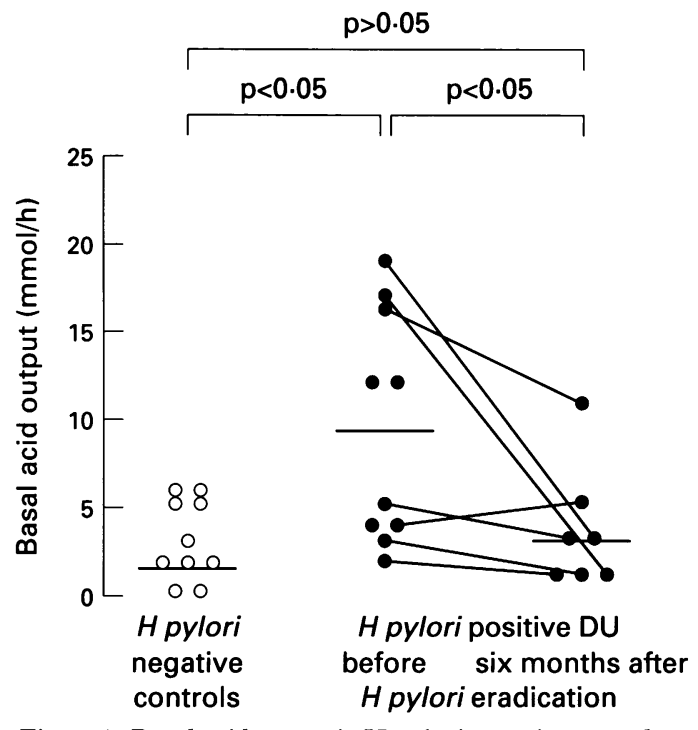

Figure 1: Basal acid output in $\mathrm{H}$ pylori negative controls (O) and patients with $D U$ (๑) before and six months after $\mathrm{H}$ pylori eradication. Horizontal bars are medians.

with haematoxylin and eosin and Gimenez stains), culture (antral and duodenal bulb specimens isolated in selective and non-selective media, and microaerobic conditions for up to 10 days), and by the ${ }^{13} \mathrm{C}$-urea breath test (European Standard Protocol, where a result is positive if excess $\delta^{13} \mathrm{CO}_{2}$ excretion exceeds 5 per $\mathrm{mil}^{8}$ ). Subjects were defined as $H$ pylori positive if the breath test and at least one other test was positive, and $H$ pylori negative if the breath test, histology, and culture were negative.

\section{Gastric acid output}

Gastric secretion studies were performed using a standard method. ${ }^{2}$ Within seven days of the endoscopy and after an overnight fast, a nasogastric tube (Salem sump tube, 90-120 cm long, 10-14 French, Sherwood Medical, West Sussex) was positioned in the most dependent part of the stomach by the water recovery test. The stomach was aspirated continuously using a suction pump (KV-4, Keymed Limited, Essex) at a negative pressure of 30 to $50 \mathrm{~mm} \mathrm{Hg}$. GRP (Cambridge Research Biochemicals, Cheshire, England) was purchased in $0.5 \mathrm{mg}$ aliquots of freeze dried lyophilised powder and prepared by the Central Middlesex Hospital Pharmacy under sterile conditions. Each aliquot was made up according to the supplier's instructions, into a one litre stock solution by dissolving in $0.9 \%$ sodium chloride; $25 \mathrm{ml}$ of $5 \%$ albumin was added to stabilise the solution.

The stomach was emptied and one 30 minute basal aspirate was collected. Immediately after the BAO collection, GRP was infused into a dorsal vein of the hand using a syringe driver (Flo-Gard DSP, Baxter Healthcare, Berkshire) at $40 \mathrm{pmol} / \mathrm{kg} / \mathrm{h}$ for 45 minutes; three consecutive 15 minute stomach aspirates were collected. ${ }^{9}$ The GRP infusion was followed by a 30 minute unstimulated period to allow plasma GRP concentrations to return to normal, ${ }^{10-12}$ while gastric secretion was continuously aspirated and discarded. Immediately after the unstimulated period, pentagastrin $6 \mu \mathrm{g} / \mathrm{kg}$ (Peptavlon, ICI Pharmaceuticals, Cheshire, England) was injected into the triceps muscle and three consecutive 15 minute aspirates collected. Four subjects (two in each group) experienced transient nausea after the pentagastrin injection, but recovered fully. No adverse effects were reported during GRP infusion.

All aspirates were stored at $+4^{\circ} \mathrm{C}$ until analysed. Titratable acidity (mmol/l) was measured with a Metrohm auto-titrator (V A Howe and Co, Banbury, England) by titration to $\mathrm{pH} 7 \cdot 0$ with $0.01 \mathrm{M}$ sodium hydroxide. Acid output $(\mathrm{mmol} / \mathrm{h})$ was calculated as the product of volume (l) and titratable acidity ( $\mathrm{mmol} / \mathrm{l})$. The two consecutive 15 minute samples with highest acid secretion were used to calculate 30 minute peak acid output, which was then doubled and expressed as $\mathrm{mmol} / \mathrm{h}^{2}$

\section{Statistical methods}

Normally distributed data are expressed as means and Student's unpaired $t$ test used to compare the significance of the difference between the group means. Acid outputs are non-Gaussian and data were expressed as medians and ranges. Wilcoxon signed rank (for paired) and Mann-Whitney (for unpaired) tests were used to compare the significance of the difference between the group medians, where $p<0.05$ was considered to be statistically significant.

Ethics

The protocol was approved by the Parkside ethical committee and all subjects gave written informed consent.

\section{Results}

Basal (BAO) and stimulated $\left(\mathrm{PAO}_{\mathrm{GRP}}\right.$, $\mathrm{PAO}_{\mathrm{Pg}}$ ) acid outputs $(\mathrm{mmol} / \mathrm{h})$ were significantly $(\mathrm{p}<0.05)$ higher in $H$ pylori positive patients with DU than $H$ pylori negative controls, with median (range) BAO 9 (2-19) $v$ $2(0 \cdot 2-6), \mathrm{PAO}_{\mathrm{GRP}} 31(0 \cdot 3-55) v 11(1-25)$ and $\mathrm{PAO}_{\mathrm{Pg}} 43(19-69) v 22(12-40)$, respectively (Figs 1-3).

Of the 10 patients with DU, eight agreed to be restudied after $H$ pylori eradication. At endoscopy all DUs had healed, with no evidence of duodenitis. $\mathrm{BAO}$ and $\mathrm{PAO}_{\mathrm{GRP}}$ are available for seven of these eight patients, due to a technical error in one. Six months after $H$ pylori eradication, median (range) $\mathrm{BAO}$, $\mathrm{PAO}_{\mathrm{GRP}}$, and $\mathrm{PAO}_{\mathrm{Pg}}$ were $3(1-11), 11$ $(0 \cdot 9-39)$, and 29 (8-52), respectively (Figs $1-3)$; all significantly $(p<0.05)$ lower than before $H$ pylori eradication, and not significantly different from the outputs in the $H$ pylori negative controls.

The median (range) per cent decrease after eradication of $H$ pylori was not significantly different for the three variables of acid output measured: BAO 50\% (20-94), $\mathrm{PAO}_{\mathrm{GRP}} 55 \%$ (15-60), and $\mathrm{PAO}_{\mathrm{Pg}} 33 \%$ (9-76). 


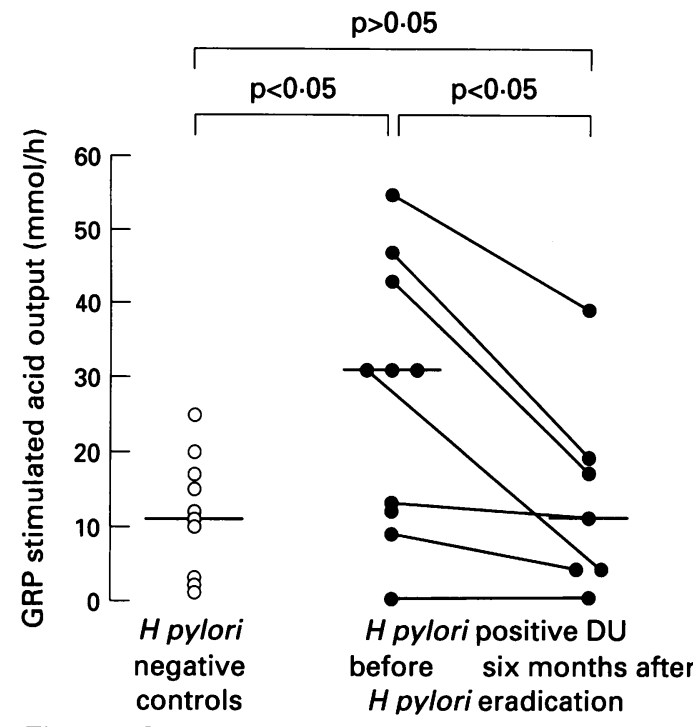

Figure 2: GRP stimulated peak acid output in $\mathrm{H}$ pylori negative controls (O) and patients with $D U(\bullet)$ before and six months after $\mathrm{H}$ pylori eradication. Horizontal bars are medians.

\section{Discussion}

This study has shown that basal, GRP, and pentagastrin stimulated acid outputs are higher in $H$ pylori positive patients with DU than in $H$ pylori negative controls, but decrease significantly six months after $H$ pylori eradication and DU healing, to fall within the range of controls.

\section{$B A O$}

As expected, $H$ pylori positive patients with DU in this study had significantly higher median BAO than $H$ pylori negative controls. Six months after $H$ pylori eradication BAO fell by a median of $50 \%$, to within the range of $\mathrm{H}$ pylori negative controls. These findings agree with those of Moss et al ${ }^{3}$ and El-Omar et al ${ }^{4}$ (Table I). Fullarton et $a l^{5}$ could not show a significant fall in BAO one month after $H$ pylori eradication in eight (seven female) patients with DU. Mean BAO $(10.7 \mathrm{mmol} / \mathrm{h})$ in this group of predominantly female patients with $\mathrm{DU}$ is higher than that reported by others in $H$ pylori positive patients with DU, 346713 and may represent a subset of patients with gastric acid basal hypersecretion.

\section{$P A O_{\mathrm{GRP}}$}

$\mathrm{El}-\mathrm{Omar}$ et $\mathrm{al}^{4}$ infused GRP $40 \mathrm{pmol} / \mathrm{kg} / \mathrm{h}$ for 45 minutes in nine $H$ pylori negative controls and $11 \mathrm{H}$ pylori positive patients with $\mathrm{DU}$ and found the median acid output $(\mathrm{mmol} / \mathrm{h})$ in the $H$ pylori positive patients with DU ( 37 , range 8.5-57) was about six times that of the controls (5.5, range 1-9). One month after $H$ pylori eradication acid output in these patients fell by a median of $66 \%$ to a median value of 13.7 $\mathrm{mmol} / \mathrm{h}$ (range $6.2-24)(\mathrm{p}<0.01)$, and fell further to $7.5 \mathrm{mmol} / \mathrm{h}$ (median $80 \%$ fall) at the end of one year (Table I). ${ }^{14}$ Our results confirm those of El-Omar et al, in that the $H$ pylori positive patients with DU have an exaggerated acid response to GRP. However, the median PAO $_{\mathrm{GRP}}$ acid output in $H$ pylori positive patients with DU (31, range $0 \cdot 3-55)$ in this study was only about threefold higher than in the $H$ pylori negative controls (11, range 1-25). These differences in the magnitude of GRP stimulated acid output between the two studies may be due to technical factors (McColl's group used acetic acid to stabilise the GRP solution, while albumin was used in this study), or to differences in the patient populations (Glasgow has a high incidence of severe DU), but do not change the general pathophysiological import of the findings.

It is interesting to compare the data in this study with those of Hirschowitz et al. ${ }^{15}$ They studied the acid response to bombesin in patients with DU and healthy volunteers before the discovery of $H$ pylori. Acid output to bombesin was increased about threefold in the patients with DU in agreement with the results of this study, but again in contrast with the sixfold increase reported by El-Omar et al. ${ }^{4}$

One of the $H$ pylori positive patients with DU had a very low acid output to GRP $(0.3$ $\mathrm{mmol} / \mathrm{h}$ ), possibly as a result of technical error, but excluding this value did not change the overall results. McColl's group have never found a GRP stimulated acid output in $H$ pylori positive patients with DU of less than $15 \mathrm{mmol} / \mathrm{h}$ (personal communication), which would explain their minimal overlap with $H$ pylori negative controls. In contrast, in this study, four of $10 \mathrm{H}$ pylori positive patients with DU had PAO $_{\mathrm{GRP}}$ of less than $15 \mathrm{mmol} / \mathrm{h}$, and five of the values were within the range of $H$ pylori negative controls. In our study PAOGRP fell by a median of $55 \%$ (similar to ElOmar et al ${ }^{4}$ ) to a median value of $11 \mathrm{mmol} / \mathrm{h}$ at six months after $H$ pylori eradication. It may be that $\mathrm{PAO}_{\mathrm{GRP}}$ initially falls rapidly during the first month after $H$ pylori eradication and then decreases more slowly thereafter.

Kovacs et al ${ }^{16}$ measured $\mathrm{PAO}_{\mathrm{GRP}}(50$ $\mathrm{pmol} / \mathrm{kg} / \mathrm{h}$ ) in eight $H$ pylori positive patients with DU and $16 \mathrm{H}$ pylori negative controls, and could not show any significant differences in acid secretion between the two groups.

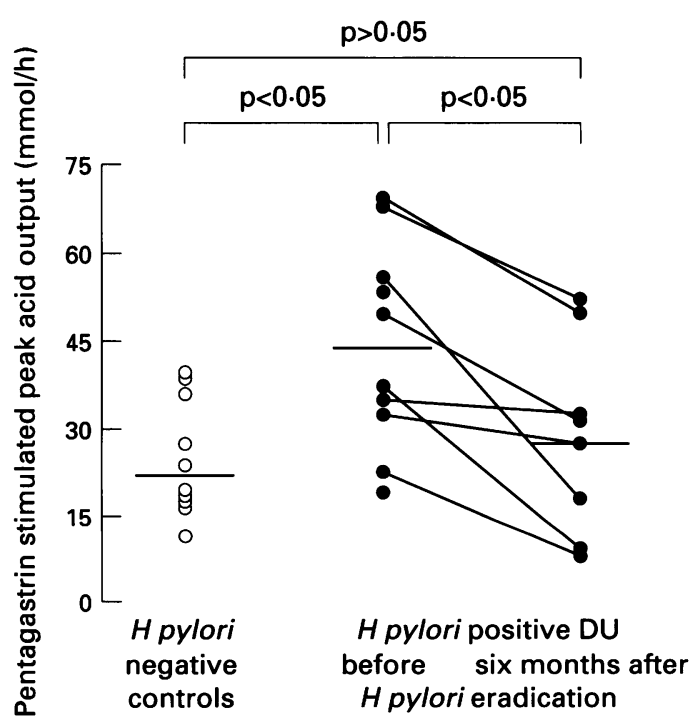

Figure 3: Pentagastrin stimulated peak acid output in $\mathrm{H}$ pylori negative controls (O) and patients with DU (๑) before and six months after $\mathrm{H}$ pylori eradication.

Horizontal bars are medians. 
Somewhat surprisingly, there was no significant difference in $\mathrm{PAO}_{\mathrm{Pg}}$ between their patients with DU and their healthy controls. The reasons for these discordant results are unclear.

$P A O_{\mathrm{Pg}}$

Peak acid output after a maximal dose of pentagastrin is a measure of the total population of functional parietal cells, ${ }^{17}$ unlike PAOGRP, which measures the combined functional response of the antrum ( $G$ and $D$ cells) and body (parietal cells) to endogenous gastrin. ${ }^{18}$ Chronic $H$ pylori infection is associated with hypergastrinaemia, which returns to within the range of $H$ pylori negative controls after $H$ pylori eradication. ${ }^{4}$ Gastrin has a trophic effect on parietal cells and may increase their number in patients with $D U,{ }^{19}$ leading to an increase in $\mathrm{PAO}_{\mathrm{GRP}}$ in $H$ pylori positive patients with $\mathrm{DU},{ }^{3-7}$ as first proposed by Levi et al. ${ }^{20}$

The hypothesis under test was that $\mathrm{PAO}_{\mathrm{Pg}}$ would decrease after $H$ pylori eradication: it did. However, Moss et $\mathrm{al}^{3}$ and Chiba et $\mathrm{al}^{7}$ could not show a significant fall in $\mathrm{PAO}_{\mathrm{Pg}}$ one month after $H$ pylori eradication (Table I). In this study $\mathrm{PAO}_{\mathrm{Pg}}$ was re-measured six months after $H$ pylori eradication. This suggests that the lack of change in earlier studies may have been due to a short follow up period. The half life of parietal cells in mice is between 23-42 days ${ }^{21} 22$ and probably longer in humans. Thus it could take many months for the trophic effect of the $H$ pylori induced hypergastrinaemia on parietal cells to decrease; our data suggest that this has occurred by six months. Nevertheless, two groups ${ }^{56}$ have measured $\mathrm{PAO}_{\mathrm{Pg}}$ one year after $H$ pylori eradication, but did not record any significant changes (Table I). Moss et $a l^{6}$ found no significant change in $\mathrm{PAO}_{\mathrm{Pg}}$ one year after $H$ pylori eradication in six patients with DU. They report $33 \% \mathrm{H}$ pylori reinfection at one year, which is very high in comparison with other published data. It may be that their diagnostic methods (antral rapid urease test) used to determine $H$ pylori status produced a high incidence of false negatives, making it possible that $\mathrm{PAO}_{\mathrm{Pg}}$ was measured in both $H$ pylori negative and positive patients. Fullarton et $a^{5}$ could not show significant changes in $\mathrm{MAO}_{\mathrm{Pg}}$ one year after $H$ pylori eradication in patients with DU $(n=6)$. Surprisingly, only one of their eight patients with DU was male, so that at follow up at least five of six were women. This female predominance might explain the comparatively low $\mathrm{MAO}_{\mathrm{Pg}}(34.7 \mathrm{mmol} / \mathrm{h})$ at the start of the study. As DU is about four times commoner in men than women, it is possible that the preponderance of women in this study may represent an atypical subset of DU disease.

In this study PAO $_{\mathrm{Pg}}$ was measured 30 minutes after an infusion of GRP. A 30 minute interval after the end of the GRP infusion and before pentagastrin was based on pharmacokinetic studies of GRP/bombesin (closely related to GRP with similar effects on gastrointestinal function ${ }^{23}$ ) intravenous infusions in humans.
These had shown that plasma gastrin and GRP concentrations return to pre-infusion values by 30 minutes after the end of GRP/bombesin infusions. ${ }^{1011}$ Ghatel et al ${ }^{10}$ infused bombesin $(0.75$ and $2.4 \mathrm{pmol} / \mathrm{kg} / \mathrm{min})$ and found a rapid decline of plasma bombesin, with disappearance half time of about three minutes. Plasma gastrin concentrations increased during bombesin infusions, but returned to preinfusion values within 30 minutes of stopping the bombesin. Wood et al ${ }^{11}$ infused GRP at about $40 \mathrm{pmol} / \mathrm{kg} / \mathrm{h}$ in six healthy human volunteers. GRP produced a large rise in plasma GRP and gastrin, which both returned to pre-infusion values within 30 minutes of stopping the GRP infusion. Finally, a study using bombesin infusion showed that pentagastrin stimulated acid output returned to prebombesin values within 20 minutes of stopping the bombesin. ${ }^{12}$

On the basis of this information it was felt that a 30 minute washout was enough to ensure that the GRP test did not interfere with the pentagastrin test. Furthermore, since the initial publication of our results, ${ }^{24}$ two other groups have confirmed our findings that pentagastrin stimulated peak acid output falls significantly after eradication of $H$ pylori. ${ }^{25} 26$ Neither of these investigators used the GRP test before pentagastrin.

What is the significance of the fall in BAO, $\mathrm{PAO}_{\mathrm{GRP}}$, and $\mathrm{PAO}_{\mathrm{Pg}}$ ? It has been recognised for some time that patients with DU have higher acid outputs ${ }^{2}$ and a larger parietal cell mass ${ }^{17}$ than controls. The importance of acid hypersecretion in the pathogenesis of DU is underlined by healing of DU on treatment with antisecretory drugs; longterm inhibition of acid can prevent recurrence of DU. Eradication of $H$ pylori heals and decreases recurrence of DU. ${ }^{1}$ Our findings suggest that this may be related, at least in part, to decreased acid output. $H$ pylori infection probably impairs the inhibitory control of gastric acid secretion, thought to be mediated largely through somatostatin. ${ }^{27}$ The increased $\mathrm{PAO}_{\mathrm{GRP}}$ in $H$ pylori positive patients with $\mathrm{DU}$ may be caused by a combination of exaggerated gastrin release and acid response to gastrin as a result of impaired inhibition from somatostatin. ${ }^{14}$ Our findings and those of El-Omar et $a l^{414}$ have shown that this abnormal response to GRP resolves after $H$ pylori eradication, probably from increased somatostatin release after $H$ pylori eradication. ${ }^{27}$ The fall in PAO $_{\mathrm{Pg}}$ after $H$ pylori eradication may be caused by decreased parietal cell mass, but other factors, such as decreased sensitivity of the parietal cells to gastrin, cannot be ruled out.

In summary, our findings have confirmed that basal and stimulated acid outputs are increased in $H$ pylori positive patients with DU, and that $\mathrm{BAO}$ and $\mathrm{PAO}_{\mathrm{GRP}}$ decrease significantly six months after $H$ pylori eradication and DU healing, to fall within the range of controls. Furthermore, we have shown a significant decrease in $\mathrm{PAO}_{\mathrm{Pg}}$ in $H$ pylori positive patients with DU after $H$ pylori eradication. These findings are compatible with a 
model that acid hypersecretion in duodenal ulcer disease is caused by $H$ pylori infection. Ulcer healing and decreased incidence of relapse of DU after $H$ pylori eradication must thus depend, at least in part, on smaller amounts of acid reaching the duodenal bulb; but other factors, such as resolution of inflammatory changes in the gastric mucosa, ${ }^{28}$ could also be important.

We thank $\mathrm{Mr}$ Kang $\mathrm{Li}$, Department of Surgery, Royal Postgraduate Medical School, and nurses of the Endoscopy Postgraduate Medical School, and nurses of the Endoscopy
Unit at St Mary's Hospital, and Ms Bernie O'Connor and Ms Mandy Butcher from the Central Middlesex Hospital Endoscopy Unit for their expert help.

1 Forbes GM, Glaser ME, Cullen DJE, Warren JR, Christiansen KJ, Marshall BJ, et al. Duodenal ulcer treated with Helicobacter pylori eradication: seven year follow-up. Lancet 1994; 343: 258-60.

2 Baron JH. Clinical tests of gastric secretion. London: Macmillan Press, 1978.

3 Moss SF, Calam J. Acid secretion and sensitivity to gastrin in patients with duodenal ulcer: effect of eradication of Helicobacter pylori. Gut 1993; 34: 888-92.

4 El-Omar E, Penman I, Dorrian CA, Ardill JES, McColl KEL. Eradicating Helicobacter pylori infection lowers gastrin mediated acid-secretion by two thirds in patients gastrin mediated acid-secretion by two thirds
with duodenal ulcer. Gut 1993; 34: 1060-5.

5 Fullarton GM, Chittajallu R, McColl KEL. Effect of eradication of $\mathrm{H}$ pylori on acid secretion in duodenal ulcer patients. Gastroenterology 1991; 100: A68.

6 Moss S, Ayesu K, Calam J. Gastrin and gastric acid output 1 year after eradication of Helicobacter pylori in duodenal ulcer patients. Regul Pept 1991; 35: 251 .

7 Chiba N, Jacobson K, Rademaker JW, Hunt RH. Parietal cell sensitivity - the effect of eradicating $\mathrm{H}$ pylori in DU patients vs normal volunteers. Gastroenterology 1993; 104: A53.

8 Logan RPH, Polson RJ, Misiewicz J, Rao G, Karim NQ, Newell D, et al. Simplified single sample ${ }^{13}$ Carbon urea breath test for Helicobacter pylori: comparison with histobreath test for Helicobacter pylori: comparison with histo-

logy, culture and ELISA serology. Gut 1991; 32: 1461-4.
El-Omar E, Penman I, Ardill JES, McColl KEL. The GRP test: a new clinical test of acid secretion. Gut 1993; 34 (suppl 1): S13.

10 Ghatel MA, Jung RT, Stevenson JC, Hillyard CJ, Adrian TE, Lee YC, et al. Bombesin: action on gut hormones and calcium in man $f$ Clin Endocrinol Metab 1982; 54: 980-5.

11 Wood SM, Jung RT, Webster JD, Ghatei MA, Adrian TE, Yanaihara $\mathrm{N}$, et al. The effect of the mammalian neuropeptide, gastrin releasing peptide (GRP), on gastrointestinal and pancreatic hormone secretion in man. Clin Sci 1983; 65: 365-71.

12 Helman CA, Hirschowitz BI. Divergent effects of bombesin and bethanechol on stimulated gastric secretion in duodenal ulcer and in normal men. Gastroenterology 1987; 92: 1926-33.

13 Levi S, Beardshall K, Desa LA, Calam J. Campylobacter pylori, gastrin, acid secretion and duodenal ulcers. Lancet 1989; ii: 613 .

14 El-Omar E, Penman I, Ardill JES, McColl KEL. The exaggerated acid response to GRP in DU patients completely gerated acid response to GRP in DU patients completely
resolves following eradication of H pylori. Gut 1993; 34 resolves following

15 Hirschowitz BI, Tim LO, Helman CA, Molina E. Bombesin and G-17 dose responses in duodenal ulcer and controls. Dig Dis Sci 1985; 30: 1092-103.

16 Kovacs TOG, Sytnik B, Walsh JH. Helicobacter pylori infection does not produce increased gastrin-stimulated acid secretion. Gastroenterology 1994; 106: A112.

17 Card WI, Marks LN. The relationship between acid output of the stomach following 'maximal' histamine stimulation and the parietal cell mass. Clin Sci 1960; 19: 147-52.

18 El-Omar EM, Penman ID, Spence E, Ardill JES, McColl KEL. The GRP test: a new clinical test of acid secretion reproducibility data. European fournal of Gastroenterology reproducibility data. European foun

19 Crean GP, Marshall MW, Ramsey RDE. Parietal cell hyperplasia induced by the administration of pentagastrin to rats. Gastroenterology 1969; 57: 147-55.

20 Levi S, Beardshall K, Haddad G, Playford R, Ghost P, Calam M. Campylobacter pylori and duodenal ulcers: the gastrin link. Lancet 1989; i: 1167-8.

21 Ragins $H$, Wincze $F$, Dittbrenner $M$. The origin and survival of gastric parietal cells in the mouse. Anat Rec 1968; 162: 99-110.

22 Karam SM. Origin, migration and fate of mouse parietal cells. Gastroenterology 1990; 98: A659.

23 Delle Fave G, Kohn A, De Magistris L, Annibale B, Bruzzone R, Sparvoli C, et al. Effects of bombesin on gastrin and gastric acid secretion in patients with duodenal ulcer. Gut 1983; 24: 231-5.

24 Harris AW, Gummett PA, Phull PS, Jacyna MR, Misiewicz JJ, Baron JH. Recurrence of duodenal ulcer after Helicobacter pylori eradication is related to high acid output. Gut 1995; 36 (suppl 1): A50.

25 Jacobson $\mathrm{K}$, Chiba N, James C, Armstrong D, Barrientos $M$, Hunt $\mathrm{RH}$. Protracted gastric acid secretion in $\mathrm{H}$ pylori positive DU patients following eradication. Gastroenterology 1995; 108: A122.

26 Parente F, Maconi G, Sangaletti O, Minguzzi M, Vago L, Bianchi Porro G. Behaviour of acid secretion, gastrin release, serum pepsinogen I, and gastric emptying of release, serum pepsinogen I, and gastric emptying of
liquids over six months from eradication of Helicobacter liquids over six months from eradication of Helicobacter pylori in duodenal

27 Moss SF, Legon S, Bishop AE, Polak JM, Calam J. Effect of Helicobacter pylori on gastric somatostatin in duodenal ulcer disease. Lancet 1992; 340: 930-2.

28 Valle J, Seppälä K, Sipponen P, Kosunen T. Disappearance of gastritis after eradication of Helicobacter pylori. A morphometric study. Scand 7 Gastroenterol 1991; 26: 1057-65.

29 Graham D. Helicobacter pylori: its epidemiology and its role in duodenal ulcer disease. $f$ Gastroenterol Hepatol 1991; 6: 105-13. 